\title{
MODELOS PEDAGÓGICOS EXPLÍCITOS E A CONSTRUÇÃO DE UMA PEDAGOGIA PARA BEBÊS E CRIANÇAS BEM PEQUENAS BASEADA NO BRINCAR
}

\author{
Alessandra Giriboni de Oliveira ${ }^{\mathrm{i}}$
}

\begin{abstract}
RESUMO: Este artigo discute os modelos pedagógicos considerados explícitos a partir das cinco características de uma pedagogia de qualidade na creche enunciadas por Araújo (2014; ARAÚJO; MONTEIRO, 2017) representados pela Abordagem Pikler (2010; FALK, 2011) e seu conceito do brincar livre, pelos pressupostos de Goldschmied e Jackson (2006) no brincar heurístico acrescido de contribuições de Kishimoto (1993, 2008, 2010, 2011, 2013) e RossettiFerreira $(2004,2006)$ relativas ao brincar dos bebês e à formação dos professores na creche como possibilidade de rede de significação na construção de uma pedagogia para bebês e crianças bem pequenas.
\end{abstract}

Palavras-chave: bebês; brincadeira; creche; modelos pedagógicos; pedagogias participativas.

\section{EXPLICIT PEDAGOGICAL MODELS AND THE CONSTRUCTION OF A PEDAGOGY FOR BABIES AND VERY YOUNG CHILDREN BASED ON PLAYING}

\begin{abstract}
This paper discusses the pedagogical models considered explicit from the five characteristics of a quality day care pedagogy, as stated by Araújo (2014; ARAÚJO; MONTEIRO, 2017) represented by the Pikler Approach (2010; FALK, 2011) and its concept of play, by the assumptions of Goldschmied and Jackson (2006) in heuristic play plus contributions from Kishimoto (1993, 2008, 2010, 2011, 2013) and Rossetti-Ferreira (2004, 2006) concerning infant play and teacher education in nursery as a possibility of building a significance in the construction of a pedagogy for babies and very young children.
\end{abstract}

Keywords: babies; play; nursery; pedagogical models; participatory pedagogies.

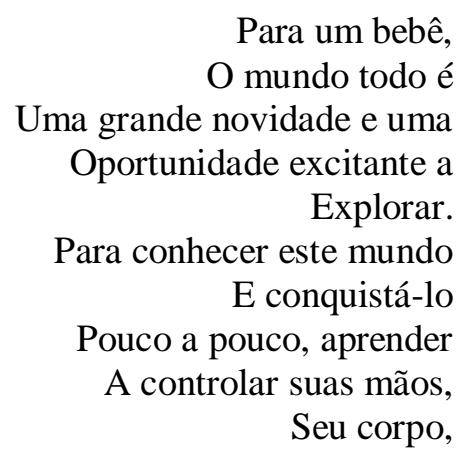

2020 Bargas; Ayoub; Assaritti, Scarazzatto, Assis. Este é um artigo de acesso aberto distribuído sob os termos da Licença Creative Commons Atribuição Não ComercialCompartilha Igual (CC BY-NC-4.0), que permite uso, distribuição e reprodução para fins não comerciais, com a citação dos autores e da fonte original e sob a mesma licença 
Os brinquedos etc.,

Ele precisará

De silêncio e

$\mathrm{Paz}$

Imperturbáveis

(TARDOS, 2012, p.1)

Ao longo de observações como pesquisadora em turmas de creches, foi possível verificar que muitas proposições feitas pelas professoras consistem em um sucedâneo de atividades promotoras de vivências fragmentadas e aligeiradas, em um esforço de aceleração dos processos de desenvolvimento e aprendizagem infantis. Por outro lado, também voltadas essencialmente às necessidades de cuidado, tal como anunciam Richter e Barbosa (2010). , Foram estas as razões mobilizadoras deste estudo que buscou elucidar e discutir acerca de pedagogias ${ }^{1}$ participativas voltadas à educação de bebês e crianças bem pequenas, fortemente marcadas pelas brincadeiras.

O documento Referenciais Curriculares Nacionais para a Educação Infantil (RCNEI, BRASIL, 1998) desconsiderou as especificidades da pedagogia dos bebês e das crianças bem pequenas e, mais recentemente, com a publicação da Base Nacional Comum Curricular (BNCC, BRASIL, 2017) surge o temo bebê em um documento curricular, embora ainda com lacunas sobre pedagogias específicas, podendo permanecer as generalizações em que os pequenos são tratados como alunos. Fochi (2013) nos alerta para as consequências dessa concepção.

Consequentemente, ao transformar as crianças em alunos, estamos atribuindo a elas uma cultura escolar já marcada pela e na sociedade, que traz consigo outros vocabulários que as naufragam em um arcabouço escolarizado. Garantir que a Educação Infantil seja habitada por crianças, coloca em voga a possibilidade de viverem atribuições de crianças, como por exemplo, brincar (FOCHI, 2013, p. $30)$.

Há de se convir que a referência a bebês em condição de coletivo suscita dúvidas e indagações sobre como propor o currículo, posto que o cuidado e a educação dos bebês possuem fortes marcas de uma cultura de cuidados domésticos, individualizados e de conhecimentos construídos no senso comum. Muitas lacunas sentidas na atualidade decorrem do histórico de políticas assistencialistas e higienistas, ratificadas pela contratação de cuidadoras mulheres no surgimento das creches, eleitas mediante frágeis critérios pautados na vocação e na maternagem.

\footnotetext{
${ }^{1}$ A pedagogia é um espaço ambíguo em triangulação constantemente renovada entre as ações, as teorias e as crenças (OLIVEIRA-FORMOSINHO; FORMOSINHO, 2013)
}

Revista Interinstitucional Artes de Educar. Rio de Janeiro, V. 6, N.2- pág. 532-555 maio-agosto de 2020: "Bebês e crianças: cultura, linguagem e políticas" 
No âmbito do currículo, Barbosa (2010) assegura que os primeiros saberes e experiências vividas com o corpo, por meio das brincadeiras e relações com outros adultos e crianças instituirão as bases sobre as quais a criança irá sistematizar os conhecimentos que fazem parte do patrimônio cultural, artístico, ambiental, científico e tecnológico. Supõe-se, portanto, que explicitar os preceitos pedagógicos que suportam as práticas educativas pode ser um bom caminho a considerar nos processos formativos dos professores no interior da creche, o que potencializaria a realização de transformações no pensar e no fazer cotidiano com os bebês.

Para Oliveira-Formosinho $(2013,2016)$ explicitar os fundamentos pedagógicos nas formações dos professores significa avançar para além da aprendizagem implícita da profissão docente até uma aprendizagem explícita de um modelo pedagógico para fazer, verdadeiramente, a pedagogia da infância; uma pedagogia participativa, plural, aberta ao pensar, fazer, dizer, ressignificar e avaliar, que afirma a competência ativa de crianças e adultos.

Nas pesquisas, dentre profissionais e contextos, Oliveira-Formosinho desenvolveu as características de uma pedagogia participativa (DEWEY, 2010; OLIVEIRA-FORMOSINHO; FORMOSINHO, 2012) e delineou as características da Pedagogia-em-Participação, considerada uma pedagogia participativa. Neste âmbito, procurou caracterizar as pedagogias transmissivas realizando os contrapontos necessários para a construção de uma pedagogia que recusa a forma escolarizante de ensinar aos professores e às crianças.

Ao tratar de inovações no contexto da creche, Oliveira-Formosinho (2016) diz que a primeira tarefa do profissional em formação é a tomada de consciência crítica sobre a pedagogia instalada na escola, especialmente àquela onde não há espaço para o respeito à competência e agência da criança. Agir nessa tomada de decisão significa desconstruir o "sempre foi assim" e trilhar um caminho que começa na aprendizagem implícita da profissão e chegar a uma aprendizagem explícita de uma gramática pedagógica para fazer pedagogia da infância. As gramáticas pedagógicas participativas são plurais (OLIVEIRA-FORMOSINHO, 2013), já a tradição é singular, pois desenvolve um currículo pronto a vestir em tamanho único (FORMOSINHO, 1987).

Para Oliveira-Formosinho (2013), a herança pedagógica deixada no século XX constitui pedagogias da infância burocráticas e centralizadas, baseadas no modelo da revolução industrial que ensina a todos como se fossem um só, currículos prontos a vestir tamanho único. Por outro lado, deixou também o desenvolvimento de modelos pedagógicos sócio construtivistas para a educação da infância considerados heranças plurais para o desenvolvimento de práticas educativas em contexto de sala de atividades. 
O conceito de modelo pedagógico refere-se a um sistema educacional compreensivo que se caracteriza por culminar num quadro de valores, numa teoria e prática fundamentada [...] Os modelos têm a vantagem de tornar explícitos os fundamentos da ação diária, isto é, os valores, as teorias e a ética subjacentes a essa ação. (FORMOSINHO, 2013, p. 16)

Nesse caso, uma gramática para o pensar, o fazer, o dizer e o avaliar o modo de viver a pedagogia em sala, que está em oposição com receitas e rituais. Patrimônio pedagógico disponível para o diálogo e construção contextos ricos em gramáticas pedagógicas participativas, como pedagogias explícitas. Pedagogias que se dizem, falam, abrem-se ao diálogo, à crítica, à aceitação e à contextualização porque são democráticas (FORMOSINHO, 2013).

Outro aspecto central da gramática pedagógica participativa como pedagogia explícita é a formação em contexto como veículo para a transformação da pedagogia da infância, porque se constitui em desenvolvimento profissional praxiológico (FORMOSINHO, 2013), visando à transformação do cotidiano pedagógico que se vive com a criança e da cultura pedagógica.

Nesse sentido, o formador é considerado um mediador pedagógico, pronto para a abertura e a escuta (FORMOSINHO, 2013) e o modo formativo deve inspirar os professores na forma como educar as crianças, sendo que o respeito que vivem enquanto formandos é o respeito que se deseja que tenham pelas crianças com quem trabalham, este é o valor isomórfico dos processos formativos respeitadores.

Resulta desta isomorfia que, qualquer que seja o modelo pedagógico adotado, os formadores tendem a impor-se como modelos de referência dos formados. Os efeitos de estruturação e de impregnação produzidos pelos dispositivos de formação correm o risco de ser mais fortes do que o discurso sustentado (FORMOSINHO; NIZA, 2009, p. 126).

Em se tratando, especificamente, do contexto da creche, as pedagogias explícitas têm sido reconhecidas como importantes para viabilizar a participação de crianças e adultos. Araújo (2014) analisou comparativamente alguns modelos pedagógicos explícitos e constatou cinco princípios centrais que definem a qualidade no contexto da creche: "(i) uma imagem de criança ativa e competente; (ii) ambiente seguro, confortável e estimulante; (iii) a centralidade das interações; (iv) as parcerias com os pais; e (v) a focalização na observação" (ARAÚJO; MONTEIRO, 2017, p. 68)

Araújo e Monteiro (2017) elucidam que modelos pedagógicos explícitos e compreensivos constituem um importante fator de qualidade na educação de infância, pois têm claras as missões e intencionalidades. Assim fundamentam que uma inovação na escola, como a adoção de uma 


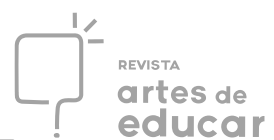

pedagogia participativa, implica convocação de conhecimento explícito, em nível dos princípios, da teoria e da ética, implicando um saber práxico resultante, simultaneamente da interação de rotinas e técnicas com as emoções, sentimentos e afetos que envolvem toda a ação humana.

A grande importância da adoção de modelos pedagógicos explícitos encontra-se fundamentalmente na atenção particular aos três primeiros anos de vida, pois não são importações ou réplicas acríticas, mas sim propostas sensíveis às particularidades dos bebês e crianças bem pequenas e aos seus contextos relacionais e materiais, construídas ao longo de décadas em ciclos de experimentação e articulação da prática à teoria considerando o brincar como meio privilegiado para aprendizagens e desenvolvimento ${ }^{2}$.

Utilizando os cinco argumentos centrais elencados para garantia de qualidade na creche (ARAÚJO; MONTEIRO, 2017), elucidaremos como dois modelos pedagógicos explícitos Goldschmied e Pikler - concebem o brincar na pedagogia da primeira infância. Posteriormente, faremos uma explanação sobre as contribuições brasileiras acerca da educação em creches Kishimoto e Rossetti-Ferreira-, também com ênfase nos estudos sobre o brincar, ação principal dos bebês e crianças bem pequenas.

\section{PEDAGOGIAS EXPLÍCITAS EM CRECHE: A PROPOSTA DE ELINOR GOLDSCHMIED E DE EMMI PIKLER}

Elinor Goldschmied dedicou boa parte de sua história aos estudos sobre a psicologia e assistência da primeira infância, teve com parceria, no trabalho e na pesquisa, Sonia Jackson. Sua experiência como consultora em creches no Reino Unido, Itália e na Escócia foi responsável pela gama de conhecimentos e exemplos de boas práticas com as crianças pequenas (GOLDSCHMIED; JACKSON, 2006).

Emmi Pikler, famosa pediatra, pesquisadora e teórica, fundou uma creche residencial após a II Guerra Mundial, em Budapeste, em 1946, com o objetivo de cuidar de crianças cujas famílias não podiam fazê-lo. O Instituto Pikler teve resultados positivos ao proporcionar a bebês e crianças uma nova possibilidade de educação e cuidados em contextos coletivos. O programa continua em funcionamento até hoje sob a direção de sua filha, Anna Tardos (GONZALEZMENA; EYER, 2014). Lóczy continua a ser a 'sede' do trabalho da Pikler, abriga a Creche Lóczy

\footnotetext{
${ }^{2}$ ARAÚJO, S.B. O 0 a 3 em foco: pensando princípios e práticas em pedagogias participativas. FEUSP, 05 de novembro de 2018 (Comunicação oral)
}

Revista Interinstitucional Artes de Educar. Rio de Janeiro, V. 6, N.2- pág. 532-555 maio-agosto de 2020: "Bebês e crianças: cultura, linguagem e políticas" 
Street, os grupos Pikler Parent-Child e profissionais altamente qualificados que não apenas ministram formação Pikler, mas também formam formadores (CARO, 2012).

Ambas deixaram em seus legados experiências e pesquisas de uma essência muito respeitosa com os bebês e crianças em instituições e escolas e representam atualmente um forte referencial para pesquisadores e educadores.

Como citado anteriormente, Araújo e Monteiro (2017) realizaram um estudo comparativo entre algumas pedagogias da infância que revelaram princípios centrais para a qualidade do trabalho no contexto da creche. Essas pedagogias estão munidas de conhecimentos explícitos e são consideradas modelos pedagógicos como janelas (OLIVEIRA-FORMOSINHO, 2007), que criam linguagem, significados e comunicação com a experiência, podendo e devendo criar um contexto de ação e reflexão-sobre-a-ação, abertas à reconstrução individual e coletiva.

O primeiro princípio elencado por Araújo (2014) ilustra a importância de quadros de referência que afirmem a competência participativa da criança, reconhecendo o direito a sua participação efetiva juntamente com o conhecimento das suas formas peculiares de reconhecer o mundo, de comunicar e construir significados. Neste sentido,

Elinor Goldschmied dedicou uma parte significativa de sua vida à formação de profissionais para a especificidade da educação de cuidados a crianças nos primeiros três anos de vida, assinalando-se, na sua obra, o respeito pelas suas idiossincrasias nas interações com pessoas e objetos. O livro escrito com sua parceira Sonia Jackson, reconhece as crianças com menos de três anos enquanto pessoas a quem devem ser proporcionadas experiências fecundas ao nível do desenvolvimento e bem-estar: as suas propostas do cesto dos tesouros ou do jogo heurístico com objetos são bons exemplos dessa premissa. (ARAÚJO; MONTEIRO, 2017, p. 68)

Por seu turno, Pikler dedicou-se a pesquisas com crianças pequenas e formação de profissionais para atuar no Instituto Pikler. Não acreditava que o bebê tivesse necessidade da intervenção direta do adulto ou de instruções para movimentar seu corpo, rejeitava a ideia de que o ser passivo se tornasse uma pessoa ativa pelo impulso do adulto. Acreditava nas possibilidades de iniciativas autônomas, de movimento livre e de jogo independente. Para ela, o adulto não deveria ter pressa e sim levar em conta as necessidades e as reações das crianças e toda a sua participação nos momentos de alimentação, banho e troca de fraldas, introduzindo por parte do adulto o respeito, que se torna um dos componentes da relação (FALK, 2008).

O segundo princípio enfatiza como central um ambiente seguro, confortável e estimulante. 
No entender de Goldschmied e Jackson é central que o ambiente suscite interesse e prazer nas crianças e adultos, incorporando elementos relativos àqueles que ali vivem, constituindo um importante instrumento de iniciação à tradição cultural. As autoras indicam a atratividade e a organização como dois elementos críticos, bem como a necessidade de salas de atividades para crianças mais pequenas combinarem de forma equilibrada a amplitude e a intimidade. (ARAÚJO; MONTEIRO, 2017, p. 69)

Pikler, para além de tratar do ambiente, acreditava que era preciso organizar um sistema tranquilo e equilibrado de vida que respeitasse o ritmo de dormir e despertar, um regime alimentar equilibrado, porém simples, definido, sobretudo, pela vontade da criança, assim como as saídas ao ar livre tanto no verão como no inverno (FALK, 2011). Resumidamente o ambiente deveria responder sempre à curiosidade do bebê em termos pessoais e materiais.

No tocante ao terceiro princípio que se refere às interações em creches, particularmente as interações adulto-criança têm adquirido maior atenção dentro das ações pedagógicas. Neste sentido, Goldschmied trata da abordagem da pessoa-chave (ELFER; GOLDSCHMIED; SELLECK, 2003), modo de trabalho centrado na construção de vínculos estreitos entre crianças e adultos específicos. Segundo Goldschmied e Jackson (2006) para o estabelecimento de relações privilegiadas entre um adulto e uma criança é fundamental a continuidade e a constância, possível a partir de uma quantidade de adulto por criança garantindo comunicação e interações próximas, atentas e prolongadas de uma educadora específica às necessidades de um grupo específico de crianças (ARAÚJO; MONTEIRO, 2017).

A abordagem Pikler, confere notável importância às interações entre o adulto e a criança. Acredita-se que desde a primeira infância, as crianças necessitam que a educadora se preocupe com ela, que lhes fale, não apenas nas horas dos cuidados, mas também durante os outros momentos do dia, especialmente de maneira positiva, não nos momentos de conflito (HEVESI; DEHELÁN, SZREDI e TARDOS, 2011). O vínculo estável e contínuo com um número reduzido de pessoas bem conhecidas e a relação privilegiada com um adulto permanente são condições fundamentais da saúde mental e do sucesso da socialização primária na primeira infância (FALK, 2008).

O quarto princípio elencado por Araújo (2014) refere-se ao fluxo de continuidade e parceria entre a família e a creche. Goldschmied salienta a importância de relações e trocas de informações entre a escola e a família, objetivando a continuidade e coerência entre os mesmos. Para a autora, as relações recíprocas de confiança se traduzem no bem-estar da criança e podem 
ocorrer de diferentes formas, inclusive no que designou jogo de relação entre as crianças e os pais (ARAÚJO; MONTEIRO, 2017).

Na abordagem Pikler, a família é o lugar de pertencimento que assegura a continuidade. Assim o contexto geral de todos os lugares que recebem crianças tem de ser concebido de maneira a assegurar a continuidade da vida da criança, desde o ambiente material, o ambiente social e o encadeamento dos acontecimentos que evitem ao mínimo as improvisações (FALK, 2008).

Finalmente, o quinto princípio central para uma pedagogia de qualidade em contexto de creche enfatiza a observação como tarefa central na ação profissional do educador, base dos processos de apoio às crianças e do planejamento cotidiano. Segundo Araújo e Monteiro (2017), a proposta de Goldschmied destaca a importância da observação atribuída à pessoa-chave, que além de observar, registra e avalia os processos das crianças. Pelo grupo reduzido de crianças recomendada pela autora, a observação torna-se mais detalhada, permitindo com conhecimento aprofundado de cada criança.

Na proposta preconizada por Pikler e continuada pelas suas colaboradoras, as educadoras observam ao mesmo tempo em que atuam e há uma terceira pessoa que acompanha a equipe e compartilha o conjunto das observações em reuniões e conversas individuais. Acreditam que a observação cria uma proximidade empática que serve de base para o relacionamento caloroso entre a criança e seu educador. A reflexão e a descrição obrigam o adulto a tomar certo recuo na sua atitude com a criança e a evitar excessos e a comunicação entre a equipe afeta o projeto pedagógico e os pequenos detalhes da vida cotidiana (FALK, 2008).

Considerando as características destes dois modelos pedagógicos que estão fundamentados em concepções, relações, espaços e materiais, além de uma lógica constante de observação e avaliação da práxis, veremos como cada uma dessas pedagogias concebe o brincar do bebê, focalizando não apenas o entorno material como também as relações que se estabelecem nesse espaço-tempo.

\section{O CESTO DE TESOUROS E A BRINCADEIRA HEURÍSTICA DE GOLDSCHMIED E JACKSON}

Goldschmied e Jackson (2006) enfatizam que na educação de qualidade para bebês e crianças é preciso que o cuidado seja responsivo às necessidades flutuantes, aos ritmos e às formas de comunicação sutilmente variadas dos bebês, ou seja, é necessário que a educadora 
conheça e promova cuidados individuais para os bebês. Os bebês, e também as crianças mais velhas, precisam de coisas interessantes e variadas, assim é imprescindível o cuidado, tanto dos ambientes, como dos brinquedos oferecidos às crianças. Nesse sentido, não são favoráveis aos brinquedos de plástico ou de materiais sintéticos que possuem uma textura desagradável ao toque, especialmente porque não portam um significado pessoal para as crianças.

As autoras dão grande valor ao brincar dos bebês e crianças pequenas, com ênfase na importância do adulto para a promoção de uma brincadeira de qualidade, pois "quanto melhor for a qualidade das oportunidades para brincar oferecidas às crianças, mais prazerosas serão as experiências, tanto para elas como para os adultos" (GOLDSCHMIED; JACKSON, 2006, p. 25).

Uma grande parte do tempo do bebê é preenchida pela alimentação e higiene. Ainda assim, com o passar do tempo, permanece por mais tempo acordado e, então, o brincar aparece como uma ação importante e vital na vida desse bebê.

O primeiro brinquedo do bebê é o corpo do adulto que cuida dele. Um bebê segura os dedos de seu pai ou de sua mãe, manipula o seio da sua mãe, enlaçando seus dedos no cabelo dela ou na barba do pai, agarrando brincos, colares, óculos [...] Porém, o bebê também precisa de oportunidades para brincar e aprender quando não está recebendo atenção de um adulto próximo. (GOLDSCHMIED; JACKSON, 2006, p. 113)

Paulatinamente, sua consciência corporal vai se ampliando e o bebê suga seu pulso, suas mãos e pés e logo que possa sentar-se terá a possibilidade de explorar o mundo dos objetos de outra maneira. Garantindo qualidade e responsividade ao interesse dos bebês, Goldschmied e Jackson (2006) desenvolveu o cesto de tesouros. O cesto de tesouros oferece uma rica variedade de objetos cotidianos, sempre escolhidos para oferecer experiências com os sentidos do tato, olfato, paladar, audição, visão e movimento corporal e nasceu das observações que as autoras faziam sobre o interesse dos bebês em mexer em objetos, abrir armários e "xeretar".

A experiência consiste que o adulto arrume uma cesta sem alça - uma cesta com alça pode sugerir que o bebê puxe ou se enrosque ao alcançar um objeto -, de um tamanho e peso que sustente o bebê caso ele se apoie, e coloque dentro desta, uma grande quantidade de objetos do cotidiano, que não sejam brinquedos, mas que podem ser arrecadados ou confeccionados e que darão uma gama de descobertas que os brinquedos de plástico não proporcionam, como: pesos, temperaturas, cores, consistências, sons, etc. Os objetos colocados na cesta devem estimular os cinco sentidos (MAJEM; ÒDENA, 2010), bem como o movimento do bebê.

Os objetos do cesto são verdadeiros instrumentos de aprendizagem (MAJEM, ÒDENA, 2010); muitos deles são utensílios domésticos de uso cotidiano ou materiais da natureza sem uma 


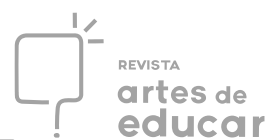

finalidade concreta. Durante a experiência com o cesto dos tesouros, os bebês exploram de diferentes formas os objetos: levam à boca, mordem, lambem, chacoalham, batem no chão, apertam, como se perguntassem: "O que é isto?"

Bruner (1995), no processo investigativo da brincadeira dos bebês com objetos, concluiu que "as crianças passam a maior parte do tempo fazendo um número muito limitado de coisas" (p. 28). No entanto, neste pequeno leque de ações, existe uma sistematicidade notável, quando em um só ato, como atirar para longe um objeto se aplica sucessivamente a um amplo número de objetos. Além disso, a criança experimenta em um só objeto diversas possibilidades motoras de que é capaz: agarrar o objeto, jogar, atirá-lo ao chão, colocar na boca, colocar sobre sua cabeça, fazendo acontecer todo um repertório.

Nessa exploração, a experiência dura o tempo em que o bebê se mantiver interessado, cabendo ao educador estar atento e dar-lhe segurança. É indicado que um cesto seja oferecido para um grupo de três bebês - garantindo que haja objetos suficientes para todos e interações entre eles - além disso, é importante que esteja em um local seguro e com possibilidades de movimentos para que os bebês possam alcançar os objetos e recolocá-los na cesta caso desejarem.

O cesto de tesouros oferece uma oportunidade para observar a interação social entre bebês em uma idade na qual se costumava dizer que eles não teriam interesse um pelo outro (GOLDSCHMIED; JACKSON, 2006). Durante a experiência, os bebês estabelecem contatos e comunicações entre si, se interessando pelo objeto que outro buscou, imitando as ações dos outros bebês e, por vezes, oferecendo o que está em suas mãos para o outro pegar.

A observação dos educadores é fundamental, podendo a cada proposta substituir alguns objetos. A presença do educador transmite aos bebês conforto emocional e confiança para que possam explorar, tranquilamente. Isso não significa que deva intervir, posto que os bebês estarão concentrados em um momento prazeroso que não requer sugestões, conselhos ou elogios (GOLDSCHMIED; JACKSON, 2006).

A experiência com o cesto de tesouros garante, individualmente, a capacidade de concentração, a utilização das mãos e dos movimentos de todo o corpo; a capacidade de escolher um dentre muitos objetos, a capacidade de exploração de um conjunto muito variado de objetos e o descobrimento de suas propriedades, que o bebê aprenda por si mesmo sem depender do adulto, a estruturação do pensamento, que o bebê aja de acordo com seu próprio ritmo e o prazer da surpresa (MAJEM; ÒDENA, 2010). 
Com o avanço do desenvolvimento das capacidades motoras do bebê, logo estarão começando a se mover pelo ambiente. "A mobilidade abre caminho para todo tipo de atividade exploratória, e é nesse estágio que a atividade de transferir coisas de dentro para fora (e viceversa) de recipientes torna-se uma ocupação que absorve sua atenção" (GOLDSCHMIED; JACKSON, 2006, p. 120). Assim, uma lata ou recipiente colocado ao lado do cesto oferecerá ao bebê a oportunidade de modificar a forma como brinca, inserindo objetos do cesto na lata e esvaziando-a.

No segundo ano de vida, as crianças têm uma curiosidade de explorar e descobrir por si mesmas a forma como os objetos se comportam no espaço quando são manipulados por elas (GOLDSCHMIED; JACKSON, 2006). Assim, precisam de uma variedade de objetos para realizar experiências e desenvolver sua concentração de uma nova forma e poderão realizá-las através do brincar heurístico ${ }^{3}$. A brincadeira heurística com objetos é, portanto, como uma continuidade da experiência com o cesto dos tesouros, porém para crianças que se locomovem, realizada em pequenos grupos, entre seis e dez crianças.

Goldschmied e Jackson (2006) preconizam que, para a realização da brincadeira heurística, o planejamento cuidadoso de alguns aspectos é necessário, a saber: o espaço, o material, o agrupamento e dois adultos envolvidos. Ainda assim, vão dizer que o brincar heurístico é uma abordagem e não uma prescrição, que não há uma maneira única de realizá-lo, desta forma, em cada localidade e instituição, os materiais separados para a realização do jogo serão sempre diferentes.

O espaço pode ser a própria sala da creche, porém, devem ser retirados outros objetos que possam distrair as crianças enquanto brincam, como os tapetes e outros brinquedos. O material é dividido em recipientes e sacolas com objetos. Os recipientes devem ser suscetíveis de conter outros objetos dentro, duráveis, podendo ser fechados por um dos lados ou com dois lados abertos, favorecendo as explorações e as combinações de objetos feitas pelas crianças.

As sacolas têm como objetivo conservar o material classificado e organizado enquanto não estiver sendo utilizado e permitir que as crianças recolham e guardem os objetos durante a brincadeira (MAJEM; ÒDENA, 2010). Indica-se que as sacolas não fiquem ao alcance das crianças, apenas dos adultos, para que não façam parte das combinações arranjadas pelas crianças, servindo apenas para classificar os objetos ao final.

\footnotetext{
${ }^{3} \mathrm{O}$ aprendizado heurístico é um sistema de educação sob o qual a aprendiz é encorajado a descobrir as coisas por si mesmo. Definição dominante na educação fundamental na Inglaterra há muitos anos.
}

Revista Interinstitucional Artes de Educar. Rio de Janeiro, V. 6, N.2- pág. 532-555 maio-agosto de 2020: "Bebês e crianças: cultura, linguagem e políticas" 
Antes da experiência, o educador organiza um amontoado contendo objetos de três ou mais sacolas e alguns recipientes para cada grupo de crianças. Podem ser organizados até três montes, o importante é que contenham os mesmos objetos, garantindo que as crianças não disputem brinquedos ou fiquem aglomeradas em apenas um monte de maior interesse.

As crianças ficam livres para brincar com os objetos e aos adultos cabe observar, registrar as combinações que as crianças fazem, manter um ambiente calmo, animar as crianças indecisas e reagrupar os objetos quando os mesmos estiverem muito espalhados. A ação de reagrupar foi avaliada como fundamental para que as crianças retomem o interesse pela experiência. As possibilidades de combinações entre os objetos são inúmeras: inserir e retirar, empilhar, sobrepor, enfileirar, classificar, construir sequências lógicas, chacoalhar, entre outras.

Goldschmied e Jackson (2006) asseveram que o brincar tem sua lógica interna. "A repetição é bastante semelhante à que ocorre com a atividade de cientistas, que desenvolvem seus conhecimentos através da repetição contínua do mesmo experimento, com pequenas variações" (p. 152).

Durante as brincadeiras das crianças com os objetos, o educador observa e registra as ações das crianças para lhe dar subsídio para o planejamento das próximas experiências. A brincadeira dura o tempo do interesse das crianças. Logo a seguir, acontece um segundo momento, não menos importante, o da recolha dos materiais. Para a recolha, o educador segura a sacola e solicita às crianças o objeto que deverá ser guardado, nomeando e localizando-os verbalmente para as crianças. Nesse momento, as crianças estão em contato com a linguagem verbal mais rica e classificam as sacolas por objetos.

Realizando a atividade com certa periodicidade, as crianças estruturam o pensamento, ampliam a compreensão verbal, já que estabelecem relações entre acontecimentos e linguagem, exercitam a concentração em sua própria ação e nas orientações da educadora, conhecem as materialidades dos objetos que manipulam e como estes se comportam quando entram em contato entre si, podem trabalhar com autonomia, com liberdade para escolher e ditar seu próprio ritmo. Sentimentos positivos de êxito e satisfação são experimentados pelas crianças, que valorizam e respeitam o material. As interações são qualificadas pela aceitação e respeito às ações de outras crianças e colaboração dos adultos. Cria-se uma atmosfera de calma e silêncio, positiva para que a atividade se desenvolva gerando um "ambiente isento de agressões mútuas, algo que com frequência se produz entre as crianças dessa idade, pela sua grande mobilidade e sua incipiente capacidade de comunicação; e adquirem hábitos de trabalho" (MAJEM; ÒDENA, 2010, p. 66).

Revista Interinstitucional Artes de Educar. Rio de Janeiro, V. 6, N.2- pág. 532-555 maio-agosto de 2020: "Bebês e crianças: cultura, linguagem e políticas" 
O cesto dos tesouros e a brincadeira heurística são duas possibilidades de brincadeiras estruturadas ricas para os bebês e crianças em contexto de creche que proporcionam aprendizagens. Importante ressaltar que, embora a experiência seja arranjada pelos educadores, ofertando riqueza e diversidade de materiais que não são brinquedos, o princípio básico dessa experiência é que a iniciativa seja das próprias crianças.

Goldschmied e Jackson (2006) abordam com clareza outras possibilidades de uso de materiais que não são brinquedos, e, portanto, não possuem uma finalidade pré-determinada, são: brincadeiras com água, areia, tecidos e caixas, blocos, etc., também citados pelas autoras. Assim como vale ressaltar que esse tipo de material é valioso nas brincadeiras das crianças maiores, quando poderão ser utilizados de maneira simbólica, substituindo objetos ausentes no campo imaginativo.

\section{O BRINCAR LIVRE NA ABORDAGEM PIKLER}

Na abordagem preconizada por Emmi Pikler o ponto central de qualquer relação do bebê com o mundo material ou pessoal é a ação autônoma, considerando que a investigação experimental descobre cada vez mais detalhes da competência da criança e a ciência mostra que "todo ato desejado e executado ativamente pelo sujeito tem para este, consequências imediatas e muito mais enriquecedoras que os hábitos impostos e suportados" (TARDOS; FEDER, 2011, p.40).

Para um bebê e uma criança, a liberdade de movimentos, dentro de condições materiais adequadas, significa a possibilidade de descobrir, experimentar, se aperfeiçoar e de viver suas posturas e movimentos (TARDOS; FEDER, 2011). Tão importante quanto a conquista de um novo movimento, são as posturas e movimentos intermediários que darão o equilíbrio e a consciência para novas posições. Assim, aquilo que caracteriza cada fase e cada criança é a tranquilidade do gesto, a harmonia do gesto aprendido, ou seja, a correção e a precisão de seus atos.

Em seu livro Moverse em libertad: desarrollo de la motricidad global (PIKLER, 2010), originalmente impresso em 1969, Emmi Pikler adverte sobre os obstáculos causados pelos adultos no desenvolvimento da motricidade global do bebê quando estes ensinam certos movimentos para o bebê. Pikler demonstra que os bebês em liberdade desenvolvem seus 
movimentos em continuidade e em ritmo regular, sentindo-se alegres e satisfeitos com cada conquista, resultando em movimentos harmoniosos com segurança e equilíbrio.

Em consonância com esta visão, o bebê nunca é colocado em uma posição que não tenha sido conquistada por si mesmo, suas roupas são sempre confortáveis, possibilitando ampla movimentação do seu corpo, as superfícies são firmes e o espaço é adequado à amplitude de movimento de cada bebê. Assim, os brinquedos/objetos devem também promover essa livre movimentação.

Respeitando o desejo que o bebê tem de ser ativo, o adulto deve organizar um entorno estimulante em função de cada criança, pois,

Para que a vida ativa de uma criança seja satisfatória para ela e para a sua educadora, é necessário que haja dois fatores fundamentais: que a criança tenha liberdade de movimentos e que tenha alguma coisa com que ocupar-se, relacionada com o seu desenvolvimento". (TARDOS; FEDER, 2011, p. 44)

No Instituto Pikler, os educadores aguardam o bebê descobrir, observar e brincar regularmente com as suas próprias mãos e, apenas quando demonstra interesse pelas coisas ao redor, é que lhe é dado algo para brincar. "Tanto a observação de suas mãos como a interação entre elas ocorrem antes e preparam para a manipulação" (KÁLLÓ; BALOG, 2017, p. 21).

O primeiro brinquedo colocado para o bebê é um pano de algodão médio de uma cor viva que atraia a atenção. $\mathrm{O}$ pano pode facilmente ser agarrado e se prende as mãos do bebê, assim ele pode observá-lo, colocá-lo no rosto ou deixá-lo cair, sem causar danos, por ser leve. Outros objetos que possam ser pegos com uma mão são colocados também ao seu alcance como uma bola de vime, um boneco de pano, entre outros. Aproximadamente, por volta dos seis meses são oferecidos brinquedos mais pesados.

Durante o primeiro semestre de vida, há o cuidado de dar a criança brinquedos de vários materiais para que ao manejá-los, acumule diferentes impressões e experiências, dependendo se são feitos de pano, madeira ou plástico. A partir do momento em que descobre como pode produzir sons com eles, seus objetos de brincar continuam sendo de diferentes materiais. (KÁLLÓ; BALOG, 2017, p. 24)

Apesar de o bebê demonstrar interesse espontâneo por novos objetos que vão sendo introduzidos, também continua gostando de brincar com o mesmo objeto por um longo período de tempo, assim descobre novas propriedades do objeto, o observa sob diferentes posições e amplia a harmonia de sua manipulação. Com o passar do tempo, as habilidades se refinam, os 
bebês passam a pegar um objeto em cada mão e seguem experimentando, chegando a colocar um objeto menor dentro de um maior.

Os diferentes cubos, cestos e baldes que pode levantar, mover e empurrar são recipientes ideais para colecionar ou agrupar outros brinquedos menores. Selecionando esses recipientes estamos já antecipando o comportamento que se manifestará nos modos de exploração da criança na idade de um ano. Por isso, é importante rodear a criança com brinquedos que lhe permitam reunir atividades tanto como explorar os momentos iniciais do construir. (KÁLLÓ; BALOG, 2017, p. 30)

Por volta de um ano o bebê começa a colecionar e construir com os objetos. Assim são oferecidos brinquedos semelhantes ou parecidos. Durante o processo de recolha, o bebê observa as diferenças e particularidades dos objetos. A maioria das crianças começa a construir a partir de suas coleções e amontoados de blocos. Uma caixa com blocos pode estar entre seus brinquedos (KÁLLÓ; BALOG, 2017).

Pikler enfatiza a importância do brincar livre e em quietude para um bebê ou criança pequena, sempre em condições de segurança que lhe proporciona uma boa relação com o adulto.

Recentemente têm ocorrido grandes discussões sobre se deixar uma criança brincar demasiadamente de forma livre poderia prejudicar seu desenvolvimento. Nós temos um ponto de vista oposto, o brincar livre, independente, sem ajuda ou incitação de quem a cuida é fundamental para o desenvolvimento. Gostamos de chamá-lo "a universidade do bebê e da criança". Porém, isso só funciona se proporcionarmos continuamente os elementos condutores externos e se a criança está ativa e ocupada, inclusive sem a presença do adulto. Mas isso só é possível para a criança que tem uma boa relação com a educadora e que se sente segura brincando, inclusive quando o adulto está fora de sua vista. É um esforço considerável dar à criança a liberdade e a quietude que requer esse tipo de brincadeira dentro de um grupo de crianças. Pensamos que o esforço vale a pena! (PIKLER apud BALOG, 2017, p. 60)

Permitindo que a criança experimente um objeto com diferentes ações, ela tem êxito e descobre suas potencialidades, percebendo que o mundo possui um sentido e que é capaz de entendê-lo. Assim, abrem-se possibilidades ilimitadas de experimentar sua competência, gerando confiança em si mesma. Ao adulto cabe manter o interesse da criança pelo mundo que a rodeia de maneira bem-sucedida, estando atento e criando condições para que a brincadeira livre e independente possa prosperar (KÁLLÓ; BALOG, 2017).

Durante a brincadeira livre, para Soares (2017), o educador tem as seguintes funções: (i) garantir segurança afetiva; (ii) preparar e transformar o ambiente; (iii) selecionar os brinquedos; 
(iv) manter a atenção, observar e interagir; (v) registrar; e (vi) interferir quando necessário, sem ser invasivo.

\section{ENCONTROS COM PEDAGOGIAS PARTICIPATIVAS BRASILEIRAS EM CRECHE E SUAS EXPLANAÇÕES SOBRE AS BRINCADEIRAS DOS BEBÊS}

Embora pesquisas e discussões acerca de bebês em contextos coletivos sejam, relativamente, tardias no Brasil em comparação a outros países, especialmente aos europeus, pela entrada recente das creches nas legislações brasileiras educacionais, enquanto direito da criança, há autores que apresentam significativa contribuição para o campo da pedagogia com bebês em creches, nacionalmente.

Serão aprofundadas as teorizações de Kishimoto (1994, 2008, 2011, 2012) e RossettiFerreira $(2004,2006)$ para a interlocução com os estudos tratados neste artigo, considerando-se a relevância de seus estudos e de seus grupos de pesquisa para os avanços das reflexões e práticas que têm se consolidado, em esfera nacional, para o campo da educação das crianças bem pequenas, com as contribuições pertinentes ao brincar do bebê.

\section{PESQUISAS E CONTRIBUIÇÕES DA PROFESSORA TIZUKO MORCHIDA KISHIMOTO}

A professora Tizuko Morchida Kishimoto é uma estudiosa pesquisadora dos jogos, brincadeiras e educação infantil, formação de professores de creches e pré-escolas, propostas pedagógicas, história, políticas públicas e letramento. No âmbito do brincar, a partir de seus estudos de Brougère, Henriot e Wittgenstein ajudou a definir os limites conceituais dos termos: jogo, brinquedo e brincadeira em nossa realidade, porque que cada contexto social constrói uma imagem de jogo conforme seus valores e modo de vida, que se expressam por meio da linguagem (KISHIMOTO, 2011).

Além disso, através de suas pesquisas, classificou as modalidades de brincadeiras que mais aparecem na educação infantil brasileira. O brinquedo educativo ou jogo educativo relaciona-se à riqueza de situações de aprendizagem que o brinquedo propicia tendo, portanto, caráter lúdico e educativo (KISHIMOTO, 2011). As brincadeiras tradicionais infantis estão relacionadas ao folclore e cultura popular brasileira. As brincadeiras de faz de conta de caráter 
imaginativo e simbólico e, por fim, as brincadeiras de construção que apoiam as brincadeiras de faz-de-conta. Apesar disso, Kishimoto (2008) frisou que o uso ou não uso de brinquedos e jogos na instituição de educação infantil varia conforme a visão que o adulto tem da criança e da escola de educação infantil.

Kishimoto $(1993,2011,2008$, 2013) fez um panorama dos principais autores que realizaram pesquisas sobre a brincadeira e indicou que poucas pesquisas demonstram a relevância do jogo no contexto cultural, sendo este um desafio para os futuros pesquisadores. Ao tratar da brincadeira do bebê, citou em seus escritos os achados de Froebel, Wallon, Piaget e Bruner. $^{4}$

Froebel diz que nos primeiros anos a criança começa a brincar com seus membros mãos, dedos, lábios, língua, pés - bem como com as expressões dos olhos e face. Conforme Kishimoto (2013, p. 69), "Froebel mostra que o bebê não está preocupado com o resultado de suas ações, que o brincar representa uma finalidade em si, que a ação motora da criança leva ao seu desenvolvimento". Também, ao observar as mães interagindo com os filhos, Froebel percebe que elas contribuem para o desenvolvimento da linguagem quando nomeiam, brincando com as partes do corpo, por exemplo (KISHIMOTO, 2013).

Wallon classificou os jogos em quatro tipos: funcionais, de ficção, de aquisição e de construção. Segundo Kishimoto (2008, p. 41) Wallon se aproxima de Vygotsky ao analisar o psiquismo infantil como resultado dos processos sociais, pois, "na origem da conduta infantil o social está presente no processo interativo da criança com o adulto que desencadeia a emoção responsável pelo aparecimento do ato de exploração do mundo".

Para Piaget, durante os primeiros 18 meses de vida predomina o jogo de exercício, que envolve a repetição de uma sequência estabelecida de ações e manipulações por mero prazer derivado da maestria de atividades motoras. Já Bruner percebeu que a brincadeira do bebê em parceria com a mãe auxilia na aquisição da linguagem, a compreensão de regras e colabora com o seu desenvolvimento cognitivo, considera que a brincadeira permite uma flexibilidade de conduta e conduz a um comportamento exploratório (KISHIMOTO, 2008).

Kishimoto foi consultora técnica especializada do Programa Currículo em Movimento sobre brinquedos e brincadeiras na educação infantil, realizado pela COEDI e MEC, visando estabelecer o diálogo das Diretrizes Curriculares Nacionais para a Educação Infantil (DCNEI, BRASIL, 2010) com os professores. No documento Anais do I Seminário Nacional: Currículo

\footnotetext{
${ }^{4}$ Os autores estão citados em ordem cronológica de nascimento. Froebel (1782-1852), Wallon (1879-1962), Piaget (1896-1980) e Bruner (1915-2016).
}

Revista Interinstitucional Artes de Educar. Rio de Janeiro, V. 6, N.2- pág. 532-555 maio-agosto de 2020: "Bebês e crianças: cultura, linguagem e políticas" 
em Movimento ${ }^{5}$, enfatizou que, embora alguns teóricos focalizem o brincar como processos imitativos das crianças, com maior destaque ao período posterior aos dois anos de idade, o brincar é a atividade principal do dia a dia e garante ações pedagógicas de maior qualidade na creche (KISHIMOTO, 2010).

Posterior ao Seminário, em 2012, o MEC lançou o Manual Brinquedos e Brincadeiras de Creches de autoria de Kishimoto e Freyberger, documento que muito tem contribuído para as reflexões nas creches brasileiras. No documento (BRASIL, 2012), a criança pequena é cidadã de direitos, deve ser cuidada e alimentada, com a educação e o brincar como questões de qualidade. Nesse aspecto, não se separa a qualidade da brincadeira da qualidade da educação infantil e que

A introdução de brinquedos e brincadeiras na creche depende de condições prévias: 1. a aceitação do brincar como direito da criança; 2. compreensão da importância do brincar para a criança vista como um ser que tem iniciativa, saberes, interesses e necessidades; 3 . criação de ambientes educativos que ofereçam oportunidades para brincadeiras e interações. (KISHIMOTO; FREYBERGER, 2012, p. 2)

As autoras trataram do brincar do bebê de 0 a 18 meses enfatizando que os bebês interagem entre si, com as crianças maiores e com a professora, movimentam-se e divertem-se, exploram brinquedos e materiais, utilizam o corpo, a boca, as mãos e os sentidos, engatinham na direção de objetos que sejam de seu interesse. Neste sentido, frisam a importância da organização dos brinquedos, de modificações contínuas na forma de estruturar o espaço da brincadeira de modo a oferecer novas oportunidades aos bebês (KISHIMOTO; FREYBERGER, 2012).

Sugerem brinquedos e materiais para os bebês que ficam deitados para experiências visuais e motoras, porém enfatizam que o primeiro brinquedo interativo de um bebê na creche é o contato físico com a professora, já que o vínculo favorece a segurança e tranquilidade do bebê. Para os bebês que sentam, indicam a possibilidade de se oferecer dois objetos ao mesmo tempo, sensoriais, de encaixe, de pôr e tirar, de bater e rabiscar e apontam que é importante permitir que os bebês interajam e se aproximem um dos outros para se comunicarem. No documento há sugestão de uso do cesto de tesouros, proposta por Elinor Goldschmied e Sonia Jackson (2006).

Os bebês que engatinham podem brincar com caixas, na grama, na areia ou subir e descer num pequeno declive, entrar em túneis, brinquedos de espuma estruturados e continuarem explorando os objetos que encaixam, colocam e tiram objetos de recipientes (KISHIMOTO;

\footnotetext{
${ }^{5}$ Disponível em: http://portal.mec.gov.br/par/195-secretarias-112877938/seb-educacao-basica-2007048997/16110-iseminario-nacional-do-curriculo-em-movimento
}

Revista Interinstitucional Artes de Educar. Rio de Janeiro, V. 6, N.2-pág. 532-555 maio-agosto de 2020: "Bebês e crianças: cultura, linguagem e políticas" 


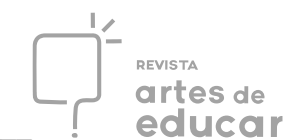

FREYBERGER, 2012). As autoras sugerem aos bebês que já andam brinquedos para empilhar, para empurrar e puxar, brinquedos de afeto e bolas diversas.

Considerando a relevância da organização dos brinquedos e materiais responsivos a cada etapa do desenvolvimento do bebê, as autoras (Ibidem) enfatizam no documento que a ação recíproca entre a criança e o professor é o fator que vai facilitar ou dificultar o diálogo, a construção de uma relação de igualdade e interações positivas e partilhadas são sempre facilitadoras para a comunicação.

\section{CONTRIBUIÇÕES DOS ESTUDOS DE ROSSETTI-FERREIRA EM CRECHES}

Maria Clotilde Rossetti-Ferreira desenvolveu projetos de pesquisa e atuação sobre apego e desenvolvimento das relações afetivas, inserção de bebês em creches, interação de bebês em creches, promoção de qualidade na educação coletiva de crianças pequenas, acolhimento familiar, institucional e adoção. Formada na teoria do apego, o envolvimento com o contexto das creches foi marcado pelo seu interesse em compreender os processos de desenvolvimento da criança que era submetida a separações diárias de suas mães. (DARAHEN; SILVA; COSTA, 2009). Porém, as situações coletivas de cuidado e educação traziam outros desafios, caracterizando-se como um contexto merecedor de ser compreendido em sua peculiaridade.

Os resultados dos estudos sobre o apego dialogam com as pesquisas que apontaram para a pobreza do ambiente (físico e relacional) como possível explicação para os efeitos perniciosos dos orfanatos no desenvolvimento das crianças, atribuindo tal prejuízo muito mais à privação geral de estímulos do que à separação ou privação da mãe propriamente dita. Assim, considerou a qualidade das creches como espaços de socialização das crianças, sem prejuízo às suas relações com a figura materna e nem ao seu desenvolvimento (ROSSETTI-FERREIRA, 2004).

Rossetti-Ferreira tornou-se uma das autoras da teoria da Rede de Significações (RedSig) marco para a psicologia do desenvolvimento no Brasil - com base nas tradições do pensamento sobre desenvolvimento ao longo do século XX: Vygotsky, Wallon, Bakhtin, Brulfert, Valsiner e Bolwby, resultado do esforço dos participantes do CINDEDI (ROSSETTI-FERREIRA, 2004). "O conjunto de fatores físicos, sociais, ideológicos e simbólicos deve ser interpretado como uma rede de significações" (DARAHEN; SILVA; COSTA, 2009, p. 200).

A perspectiva teórico-metodológica da Rede de Significações (RedSig) vem sendo elaborada de forma a constituir uma ferramenta capaz de auxiliar tanto

Revista Interinstitucional Artes de Educar. Rio de Janeiro, V. 6, N.2- pág. 532-555 maio-agosto de 2020: "Bebês e crianças: cultura, linguagem e políticas"

DOI: $10.12957 /$ riae.2020.46167 
nos procedimentos de investigação, como na composição do processo de desenvolvimento humano. Estes processos [...] são concebidos como se dando durante todo o ciclo vital, nas e através das múltiplas interações estabelecidas pelas pessoas, em contextos social e culturalmente organizados. (ROSSETTIFERREIRA; AMORIM; SILVA, 2004, p. 24).

A RedSig emergiu das discussões teórico-metodológicas relacionadas a pesquisa sobre o processo de adaptação de bebês e suas famílias à creche (ROSSETTI-FERREIRA; AMORIM; SILVA, 2004) que teve como desafio analisar uma situação de encontro entre contextos (família/creche/trabalho) dos envolvidos, através de interpretações fundamentadas na abordagem sistêmica representada por Bronfenbrenner que,

Concebe os contextos de desenvolvimento das pessoas como sistemas de estruturas aninhadas, interdependentes e em recíproca interação. Tais contextos abrangem desde políticas, ideologias e órgãos de governo, em um nível mais macro, até situações de interação face a face, denominadas de microssetings. (ROSSETTI-FERREIRA; AMORIM; SILVA, 2004, p. 18-19)

A RedSig abriu a possibilidade de se compreender a pesquisa com bebês e adultos dentro de significações próprias de cada pesquisador, obstante ao seu contexto e ao contexto pesquisado. Já que, não só as crianças, como também os adultos são coordenados pelos valores culturais do seu grupo social, pelas suas próprias definições pessoais sobre desenvolvimento infantil (sua rede particular de significações) e pelos limites sensório-motores e desenvolvimentais das crianças.

A rede particular de significações é formada pelos processos de significação da pessoa que são determinados pela história pessoal, pelos seus limites biológicos e psicológicos. Além de ser a manifestação do conjunto de fatores sócio-históricos, psíquicos e emocionais que formam e são formados pela cultura em que tal pessoa vive. Por exemplo, o conceito de que as crianças pequenas interagem apenas com outros adultos e que brinquedos são construídos culturalmente e vão sendo conservados ou alterados de acordo com as situações. Outro exemplo é que a adaptação de um bebê à creche pode ser conceituada como um processo que se inicia mesmo antes da criança entrar na creche, quando os pais estão pensando na melhor opção em relação ao futuro de seu filho (FRANCHI; VASCONCELOS; ROSSETTI-FERREIRA, 2004).

Relacionada à brincadeira, encontramos em Franchi e Rossetti-Ferreira (2004) algumas interpretações de situações observadas nas suas pesquisas a partir da perspectiva teóricometodológica da RedSig. Por exemplo: notaram que a organização dos espaços e brincadeiras 
em uma creche foi feita a partir das redes de significações pessoais da diretora e das educadoras, e que, inclusive, estas possuíam concepções conflitantes em alguns casos e em outros não.

Observando um episódio de disputa de brinquedos, os autores interpretaram sob a ótica das educadoras a partir das significações pessoais de cada uma. Uma das educadoras comparou a disputa das crianças à disputa do mundo dos adultos, a outra percebeu a disputa como algo não tão sofrido e mais prazeroso e concluíram que

Quando dizemos que as crianças dessa idade competem entre si, com certeza não estamos falando do mesmo fenômeno de competição observado nos adultos. Porém, ao reformularmos a experiência interativa das crianças na linguagem, enquanto observadores, podemos the atribuir essa qualidade. (FRANCHI; VASCONCELOS; ROSSETTI-FERREIRA, 2004, p. 148)

Desse modo, da mesma maneira que as redes de significações individuais são constituídas por crenças, saberes, valores e histórias pessoais que norteiam as ações humanas (ROSSETTI-FERREIRA, 2004), a própria pedagogia é constituída por essas significações humanas, entremeadas por ações, teorias e crenças em movimento triangular (OLIVEIRAFORMOSINHO; FORMOSINHO, 2013).

\section{CONSIDERAÇÕES FINAIS}

As pedagogias explícitas consideradas como modelos pedagógicos de qualidade em creche, representadas por Goldschmied e Jackson (2006), Pikler (1969, Falk, 2011), se convergem com as teorizações de Kishimoto (2010, 2012) e Rossetti-Ferreira (2004) ao conceber a agência do bebê e da criança como fundamentais nos processos formativos e nas práticas cotidianas, no respeito ao período sensório-motor do bebê, enfatizando a relevância dos espaços, materiais e interações responsivos a sua curiosidade e necessidade exploratória, ao considerar como brincadeiras as interações do bebê com o adulto, com seu próprio corpo, com objetos e também com seus pares. Em nível da pedagogia praticada pelos adultos consideram foco na formação continuada, pautada pelas observações e registros das práticas, considerando as significações pessoais nos processos respeitadores no âmbito da creche, valorizando a interação com as famílias e com a comunidade local.

Isto posto, os modelos pedagógicos apresentados neste estudo configuram-se como potentes no trabalho pedagógico desenvolvido em creches, especialmente por revelar princípios de qualidade baseados na ética e nas idiossincrasias de bebês e crianças bem pequenas. 


\section{REFERÊNCIAS}

ARAÚJO, S. B. Avaliação da qualidade em creche: o bem-estar e o envolvimento da criança como processos centrais. Nuances: estudos sobre Educação, Presidente Prudente - SP, v. 25, n. 3, set./dez. 2014, p. 100-115.

MONTEIRO, T. Pedagogias Explícitas em Creche: relato de uma investigação-ação em contexto português. Revista Humanidades e Inovação, Tocantins, v.4, n. 1. 2017. Disponível em: https://revista.unitins.br/index.php/humanidadeseinovacao/issue/view/20. Acesso em: 20 dez. 2017.

BALOG, G. Iniciando a construção. Objetos apropriados para a brincadeira. In: KÁLLÓ, E. BALOG, G. As origens do brincar livre. São Paulo: Editora Omnisciência, 2017.

BARBOSA, M. C. Especificidade da ação pedagógica com os bebês. In: Anais do I Seminário Nacional: Currículo em movimento - Perspectivas atuais. Belo Horizonte, novembro, 2010.

BRASIL. Referenciais Curriculares Nacionais para a Educação Infantil. Brasília: MEC/SEF, 1998. 2010 .

.. Diretrizes Curriculares Nacionais para a Educação Infantil. Brasília: MEC/SEB,

.. Brinquedos e Brincadeiras de Creche: manual de orientação pedagógica. Brasília: MEC/SEB, 2012.

Base Nacional Comum Curricular. Brasília: MEC/SEB, 2017.

BRUNER, Jerome S. El habla del niño. Barcelona: Paidós, 1995.

CARO, C. The Genius of Emmi Pikler. 2012. In: The Pikler Collection. Disponível em: https://thepiklercollection.weebly.com/history.html. Acesso em: 12 nov 2017.

DARAHEN, G. C.; SILVA, A. P. S.; COSTA, N. R. A. Da teoria de apego à Rede de Significações: Maria Clotilde Rossetti-Ferreira e a psicologia do desenvolvimento brasileira. Revista Temas em Psicologia. 2009, vol. 17, n. 1, p. 191-207. Disponível em: http://pepsic.bvsalud.org/pdf/tp/v17n1/v17n1a16.pdf. Acesso em: 30 mar. 2018.

DEWEY, J. Experiência e Educação. Petrópolis, RJ: Vozes, 2010.

ELFER, P.; GOLDSCHMIED, E.; SELLECK, D. Y. Key Persons in the early years. Reino Unido: David Fulton Books, 2003.

FALK, J. Abordagem Pikler Educação Infantil. São Paulo: Editora Omnisciência, 2008.

FALK, J. Educar os três primeiros anos: a experiência de Loczy; Tradução: Suely Amaral Mello. Araraquara, SP: Junqueira \& Marin, 2011.

Revista Interinstitucional Artes de Educar. Rio de Janeiro, V. 6, N.2- pág. 532-555 maio-agosto de 2020: "Bebês e crianças: cultura, linguagem e políticas" 
FOCHI, P.S. Mas os bebês fazem o que no berçário, heim?: documentando ações de comunicação, autonomia e saber-fazer de crianças de 6 a 14 meses em contexto de vida coletiva. Dissertação de mestrado. Universidade do Rio Grande do Sul, 2013.

FORMOSINHO, J; NIZA, S. Iniciação à prática profissional nos cursos de formação inicial de professores. In: FORMOSINHO, J. (coord.) Formação de professores: aprendizagem profissional e acção docente. Porto: Porto Editora, 2009.

FORMOSINHO, J. Prefácio. In: OLIVEIRA-FORMOSINHO (Org.). Modelos curriculares para a educação de infância: construindo uma práxis de participação. Porto: Porto Editora, 2013.

FRANCHI e VASCONCELOS, C. R.; ROSSETTI-FERREIRA, M. C. Crianças Pequenas brincando em creche: a possibilidade de múltiplos pontos de vista. In: ROSSETTI-FERREIRA, et. Al. (Orgs.) A Rede de Significações e o estudo do desenvolvimento humano. São Paulo: Editora Penso, 2004. P. 136-153.

GOLDSCHMIED, E. JACKSON, S. Educação de 0 a 3 anos: o atendimento em creche; Tradução: Marlon Xavier. Porto Alegre: Grupo A, 2006.

GONZALEZ-MENA, J. EYER, D. W., O cuidado com bebês e crianças pequenas na creche. Um currículo de educação e cuidados baseado em relações qualificadas. $9^{\mathrm{a}}$ ed. Porto Alegre: AMGH, 2014.

HEVESI, K. Relação através da linguagem entre a educadora e as crianças do grupo. In: FALK, J. Educar os três primeiros anos: a experiência de Loczy; Tradução: Suely Amaral Mello. Araraquara, SP: Junqueira \& Marin, 2011.

KÁLLÓ, E. BALOG, G. As origens do brincar livre. São Paulo: Editora Omnisciência, 2017. KISHIMOTO, T. M. Jogos Infantis. São Paulo: Editora Vozes, 1993.

O jogo e a educação infantil. São Paulo: Cengage Learning, 2008.

. (Org.) Jogo, brinquedo, brincadeira e educação. São Paulo: Cortez, 2011.

. (Org.) O Brincar e suas teorias. São Paulo: Cengage Learning, 2013.

; FREYBERGER, A. Brinquedos e Brincadeiras de creches. Brasil, MEC, SEB, 2012.

MAJEM, T.; ÒDENA, P. Descobrir brincando. Campinas, SP: Autores Associados, 2010. (Formação de professores. Serie educação infantil em movimento).

OLIVEIRA-FORMOSINHO, J. FORMOSINHO, J. Perspectiva pedagógica da Associação Criança: pedagogia-em-participação. In: KISHIMOTO, T.M., OLIVEIRA-FORMOSINHO, J. (Orgs.). Em busca da pedagogia da infância. Porto Alegre: Penso, 2013, p. 188-216.

OLIVEIRA-FORMOSINHO, J. ARAÚJO, S. B. A Pedagogia-em-Participação em creche: A perspetiva da Associação Criança. In: OLIVEIRA-FORMOSINHO, J. ARAÚJO, S. B. Educação em creche: Participação e Diversidade. Porto: Editora Porto, 2013. 
OLIVEIRA-FORMOSINHO, J. Pedagogia(s) da infância: Reconstruindo uma praxis da participação. In: OLIVEIRA-FORMOSINHO, J.; KISHIMOTO, T. M.; PINAZZA, M. A. (Org.). Pedagogia(s) da infância: Dialogando com o passado construindo o futuro. Porto Alegre: Artmed Editora, 2007, p. 13-37.

OLIVEIRA-FORMOSINHO, J. As gramáticas pedagógicas participativas e a construção da identidade da criança. Revista Textura (ULBRA). V.18.n. 36. 2016. Disponível em: http://www.periodicos.ulbra..br/index.php/txra/article/view/1747/1457. Acesso em: 10 jan. 2018. 2013.

; ARAÚJO, S. B. Educação em creche: participação e diversidade. Porto: Porto Editora,

PIKLER, E. Moverse em liberdad: desarrollo de la motricidad global. Madrid: Narcea Ediciones, 2010.

RICHTER, S. R. S; BARBOSA, M. C. S. Os bebês interrogam o currículo: as múltiplas linguagens na creche. Educação, Santa Maria, v. 35, n. 1, p. 85-96, jan./abr. 2010.

ROSSETTI-FERREIRA, M. C. Introdução - Tecemos a RedSig e este livro seguindo a receita do poeta. In: ROSSETTI-FERREIRA, et. Al. (Orgs.) A Rede de Significações e o estudo do desenvolvimento humano. São Paulo: Editora Penso, 2004. P. 16-22.

; AMORIM, K. S.; SILVA, A. P. S. Rede de Significações: alguns conceitos básicos. In: ROSSETTI-FERREIRA, et. Al. (Orgs.) A Rede de Significações e o estudo do desenvolvimento humano. São Paulo: Editora Penso, 2004. P. 24-41.

Olhando a pessoa e seus outros, de perto e de longe, no antes, aqui e depois. In: COLINVAUX,D.; BANKS, L.; DELL'AGLIO, D. D. (Orgs.). Psicologia e desenvolvimento: Reflexões e práticas atuais. São Paulo: Casa do Psicólogo, 2006, p. 19-59.

SOARES, S. M. Vínculo, movimento e autonomia: educação até 3 anos. São Paulo: Editora Omnisciência, 2017.

TARDOS, A. Deixe o bebê também brincar por si mesmo. Tradução de Patrícia Gimael. The first Years: Ngã Tau Tuatahi New Zealand Journal of Infant and Toodler Education. Volume 14, Issue I, 2012.

; FEDER, A. S. O que é autonomia na primeira infância. In: FALK, J. Educar os três primeiros anos: a experiência de Loczy; Tradução: Suely Amaral. Araraquara: JM Editora, 2011, p. 33-46.

\footnotetext{
i Doutoranda e Mestra em Educação pela Faculdade de Educação da USP (FEUSP); E-mail: alesgiriboni@hotmail.com São Bernardo do Campo/SP; ORCID: https://orcid.org/0000-0003-1902-0872
}

Revista Interinstitucional Artes de Educar. Rio de Janeiro, V. 6, N.2- pág. 532-555 maio-agosto de 2020: "Bebês e crianças: cultura, linguagem e políticas" 